Article

\title{
Effects of Population Growth and Climate Variability on Sustainable Groundwater in Mali, West Africa
}

\author{
Alexandra Lutz ${ }^{1, *}$, James M. Thomas ${ }^{1}$ and Mamadou Keita ${ }^{2}$ \\ 1 Division of Hydrologic Sciences, Desert Research Institute, 2215 Raggio Parkway, Reno NV \\ 89512, USA; E-Mail: jthomas@dri.edu \\ 2 Mali Rural Water Project, World Vision, Bla, Mali; E-Mail: mamadou_keita@wvi.org \\ * Author to whom correspondence should be addressed; E-Mail: Alexandra.Lutz@dri.edu; \\ Tel.: +1-775-673-7418; Fax: +1-775-673-7363.
}

Received: 5 November 2010; in revised form: 16 December 2010 / Accepted: 17 December 2010 / Published: 23 December 2010

\begin{abstract}
Groundwater is increasingly relied on as a source of potable water in developing countries, but factors such as population growth, development, and climate variability, pose potential challenges for ongoing sustainable supply. The effect of these factors on the groundwater system was considered in four scenarios using a numerical model to represent the Bani area of Mali, West Africa. By 2040, population growth, climate variability, and development as urbanization, agriculture, and industry creates scenarios in which groundwater extraction is an increasingly larger percentage of the groundwater system. Consumption from agriculture and industry increases extraction rates from less than 1 to $3.8 \%$ of mean annual precipitation, which will likely affect the groundwater system. For instance, concentrated pumping in local areas may result in water level declines. The results of this study contribute to an ongoing evaluation of sustainable groundwater resources in West Africa.
\end{abstract}

Keywords: groundwater; sustainability; climate; population growth

\section{Introduction}

One of the greatest challenges that developing nations currently face is providing access to sustainable safe drinking water, while successfully managing water as an environmental resource. The 
need for improved access to safe water cannot be disputed. On a daily basis, water-related diseases kill an estimated 14,000 to 30,000 people in developing nations, of which many are children [1]. Beyond human health, unsafe water impacts educational outcomes, productivity, and essentially keeps developing nations from developing. Absence from school due to water-related illness contributes to substandard school performance [2,3]. Lost productivity due to water-related illness could be reduced by more than one-third in most areas [3] if potable water were accessible. It is clear that improved access to sustainable, potable water has socioeconomic benefits. A rise in the standard of living, however, intensifies stress on environmental resources, especially water.

It should be noted that within this report, sustainable safe water pertains to availability of the groundwater resource itself, and should not be associated with the longevity of programs responsible for well development, or ongoing operation and maintenance of the hand-pumps. There are various definitions for the terms "sustainable groundwater resources." Younger [4] addresses these definitions and suggests that the "most rounded" one may be given by the South African Water Act of 1998, since it considers "Some for all, for ever-equitable allocation and utilization of water for economic social and economic benefit, through environmentally sustained practices." Within the context of this report, then, sustainability should be considered as an environmental assessment of ongoing groundwater supply in the social and economic interest of rural populations.

In the West African country of Mali, the international aid community, local governments, and various organizations are developing groundwater resources as an ongoing safe water for rural communities. While advances in public health are being made, there is growing concern over local climate variability, increasing population, and ongoing supply of safe water. By 2020, per capita freshwater supplies in Mali are projected to decline by $52 \%$ due to an increase of population and a predicted decrease in rainfall [5]. It is anticipated that the per capita decrease in freshwater sources will intensify stress on groundwater resources. If downward trends reported for precipitation and surface water availability continue, there may be negative implications for long-term supply of groundwater resources [6,7].

The Mali Rural Water Project (MRWP) and the Desert Research Institute (DRI) are working together to evaluate the supply of potable groundwater in an area of Mali. In 2005, with the assistance of West Africa Water Initiative (WAWI) partners, staff from DRI and MRWP established the Bani study area (Figure 1). The Bani study area is unique in that time-series groundwater level data are being collected at several community hand-pumps. Time-series groundwater level data are not known to be previously available in this area of Mali. Typically, demand for potable water, combined with the stipulations of water-project sponsors, emphasizes rapid and efficient development of improved sources without prioritization of hydrogeologic studies. As groundwater level data continue to become available, hydrogeologic parameters such as recharge, specific yield, and specific storage, will be better understood. Extraction rates from boreholes, which are often estimates based on manufacturer's specifications of the pump, may also be known. 
Figure 1. Location of the Bani study area in Mali, West Africa. Model boundary shown in dark red.

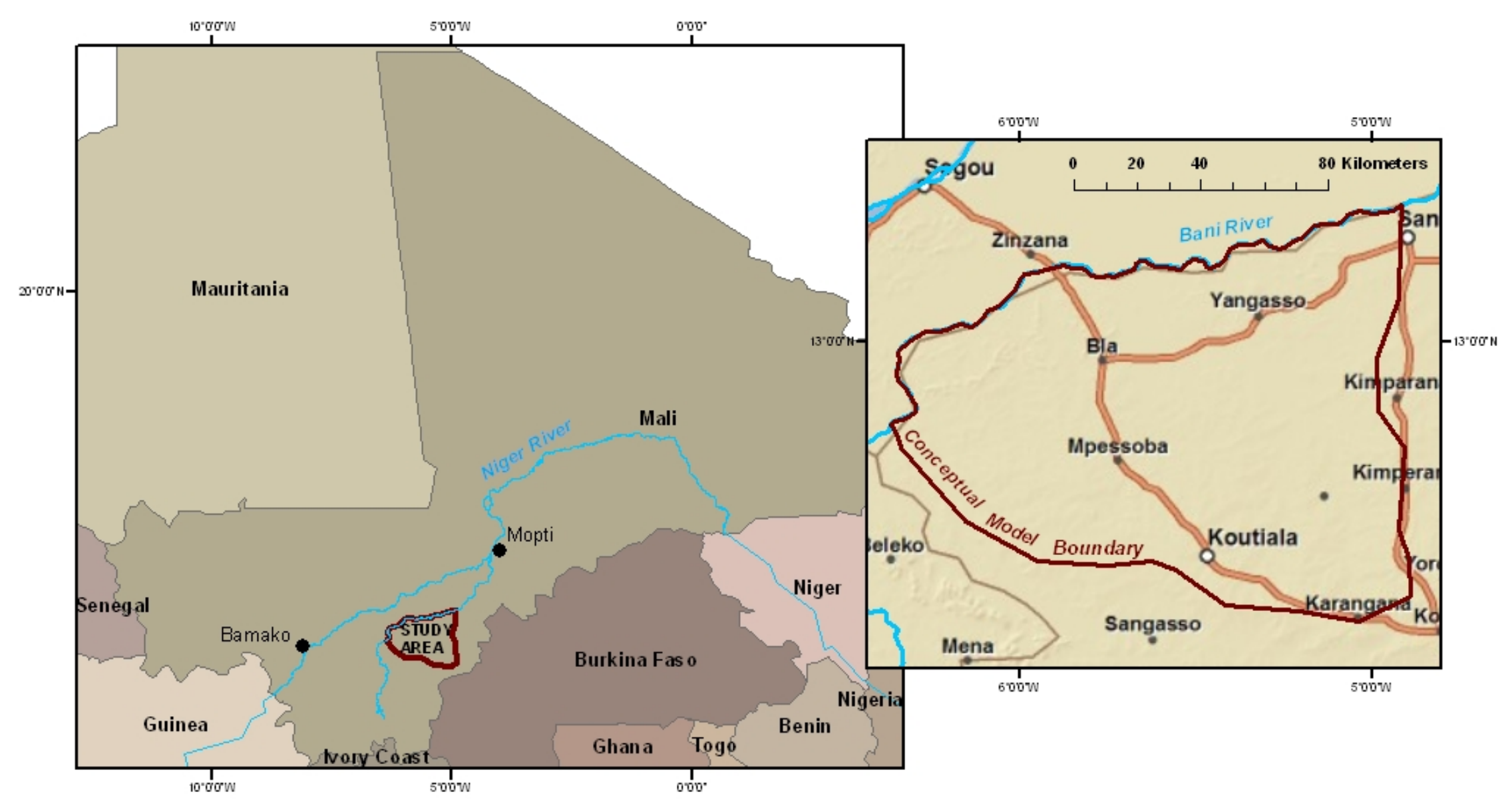


There are numerous reasons for choosing this area of Mali for a study. Data are available for climate and stream flow from the nearby community of San. The Bani River, a tributary to the Niger River, has decreased in volume as well as reduced floodwater during the past several decades, which is linked to a reduction in rainfall [6,7]. Unreliable and declining rainfall threaten smallholder, subsistence family farms, which form the backbone of the local economy. Additionally, the area covers the southern Segou Region, which is identified as one of the most highly stressed regions of Mali. Stress is based on the region being endowed with many ecosystem services which are deteriorating, high population densities, and high levels of poverty [7].

In an area of ecosystem service deterioration, high population density, and high levels of poverty, achieving the social and economic interest of the rural population includes providing each community member with opportunities to access to a minimum amount of potable water and to experience economic development via agriculture and/or industry. This study uses a groundwater flow model to evaluate four future scenarios of groundwater supply in 2040, when the population is expected to double. The scenarios consider population growth with universal access to a minimum amount of potable water, variability of climate as precipitation, and development, which includes urbanization, more intense agriculture, and industrialization. The scenarios consider development of groundwater resources only. Currently, rainwater collection is not common and development of surface water sources as safe sources is cost-prohibitive.

The overarching purpose of the Bani study area is to develop an understanding of current aquifer conditions and to make predictions of future groundwater supply under various scenarios. The results of this study form the foundation for a more robust evaluation of the groundwater system in central Mali, especially as more data become available.

\section{Developing Scenarios}

\subsection{Groundwater Model}

Creating the model was a multi-part process including model development, construction, and calibration, and developing the model entailed compiling and analyzing information about the hydrogeologic setting [8]. This study focused on a $14,376 \mathrm{~km}^{2}$ area of central Mali located between latitudes $12.12^{\circ} \mathrm{N}$ to $13.40^{\circ} \mathrm{N}$ and $4.90^{\circ} \mathrm{W}$ to $6.38^{\circ} \mathrm{W}$ (Figure 1). The topography consists of plains undulating between approximately 200 and $450 \mathrm{~m}$ above sea level (masl). Climate is controlled by migration of the Inter-Tropical Convergence Zone (ITCZ), which separates wet maritime monsoonal air from the Gulf of Guinea and Sahara Desert air from the interior of northern Africa [9]. The Bani study area is within the Sudanian Savannah Zone, a dry savannah, where precipitation ranges from 500 to $700 \mathrm{~mm} \mathrm{yr}^{-1}$ and occurs from June to October [5,7]. A dry season prevails the remainder of the year.

Data used to develop the model were compiled and analyzed from sources including: a database of MRWP well logs [10]; Global Runoff Data Center (GRDC); National Center for Atmospheric Research (NCAR); United States Geological Survey (USGS); the Centre for Environmental Economics and Policy in Africa (CEEPA); the United Nations Development Programme (UNDEP); workshop and conference proceedings; personal conversations with Peace Corps Volunteers; scientific 
journals; and unpublished reports, theses, and dissertations. In some cases, other software programs were used. For instance, stream reaches of the Bani River and its tributaries were imported from GIS coverages.

The model was constructed and run using the software GMS-MODFLOW with the recharge, river, flow, well, and evapotranspiration packages [8,11]. The Bani area was represented by a variably-spaced grid oriented along the north-south and east-west axes (Figure 2). Cell size varies from $500 \mathrm{~m}$ by $500 \mathrm{~m}$ at the center to approximately $5,761 \mathrm{~m}$ by $6,877 \mathrm{~m}$ at the edges to capitalize on better information known for the center than for outer portions. No known geologic cross-sections of the Bani or nearby areas exist, so the model consists of a single layer (bottom at 60 masl and top at land surface) representing the deepest well in the modeling area. Available well logs indicate average borehole depth, static water levels, and screen values to be 56, 15, and $42.2 \mathrm{~m}$ below land surface, respectively [10]. Groundwater extraction was based on community location by global positioning satellite coordinates. A review of the literature, limited field data, and previous modeling efforts indicated a specific yield value of 0.24 and specific storage of $10^{-4} \mathrm{~m}^{-1}$ to be reasonable estimates for consolidated sandstone [8].

Figure 2. Variably-speaced grid overlaying the Bani study area.

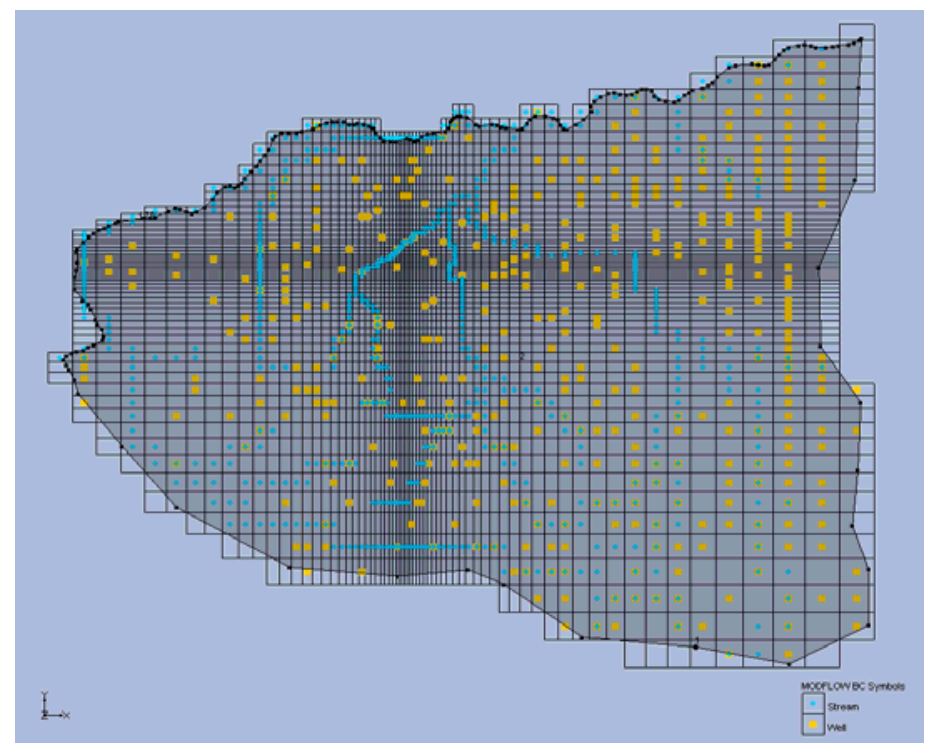

A steady-state model was developed to simulate equilibrium, when aquifer recharge and discharge were equal and long-term groundwater storage change was negligible. The steady-state model used mean annual values for input parameters. Once calibrated, it was converted to a transient model for 34 time steps, consisting of each year from 2007 through 2040. The goal of the transient model was to simulate groundwater level changes that occurred in the system due to monthly changes of input parameters. Calibration criteria included minimization of root mean square error (RMSE) between measured and simulated groundwater levels being equal to or less than $10 \%$ of the head drop across the model area and little or no discrepancy between inflow and outflow volumes. Summary statistics for calibration are listed in Table 1. More detailed calibration information are beyond the scope of this report and are listed elsewhere [8]. 
Table 1. Summary statistics for model calibration.

\begin{tabular}{ll}
\hline Number of Observations & 240 \\
Mean Error (m) & 0.04 \\
Standard Deviation Error (m) & 0.55 \\
Sum of Squares Error (m) & 73.69 \\
Mean Absolute Error (m) & 0.044 \\
Minimum Residual (m) & -1.348 \\
Maximum Residual (m) & 1.401 \\
Head Drop (m) & 36.6 \\
RMSE & 3.8 \\
RMSE/Range (\%) & $10 \%$ \\
\hline
\end{tabular}

\subsection{Population Growth}

By the year 2040, population in the Bani area is expected to approximately double. Estimates of annual growth rates are as high as $3.0 \%$ [5,7]. Population growth, however, is not distributed equally across the area. Given the trend of urbanization, population growth is proportionate to the size of communities: $3.6 \%$ for those with more than 5,000 inhabitants, $1.3 \%$ for those with 2,000 to 4,999 inhabitants, and $0.6 \%$ for those with less than 2,000 inhabitants [5]. These growth rates are applied to 1998 census data for communities in the Bani study area and projected forward each year from 2007 until 2040 (Figures 3 and 4).

Figure 3. Calculated population in Bani study area during 2007, which is the beginning of the modeling scenarios.

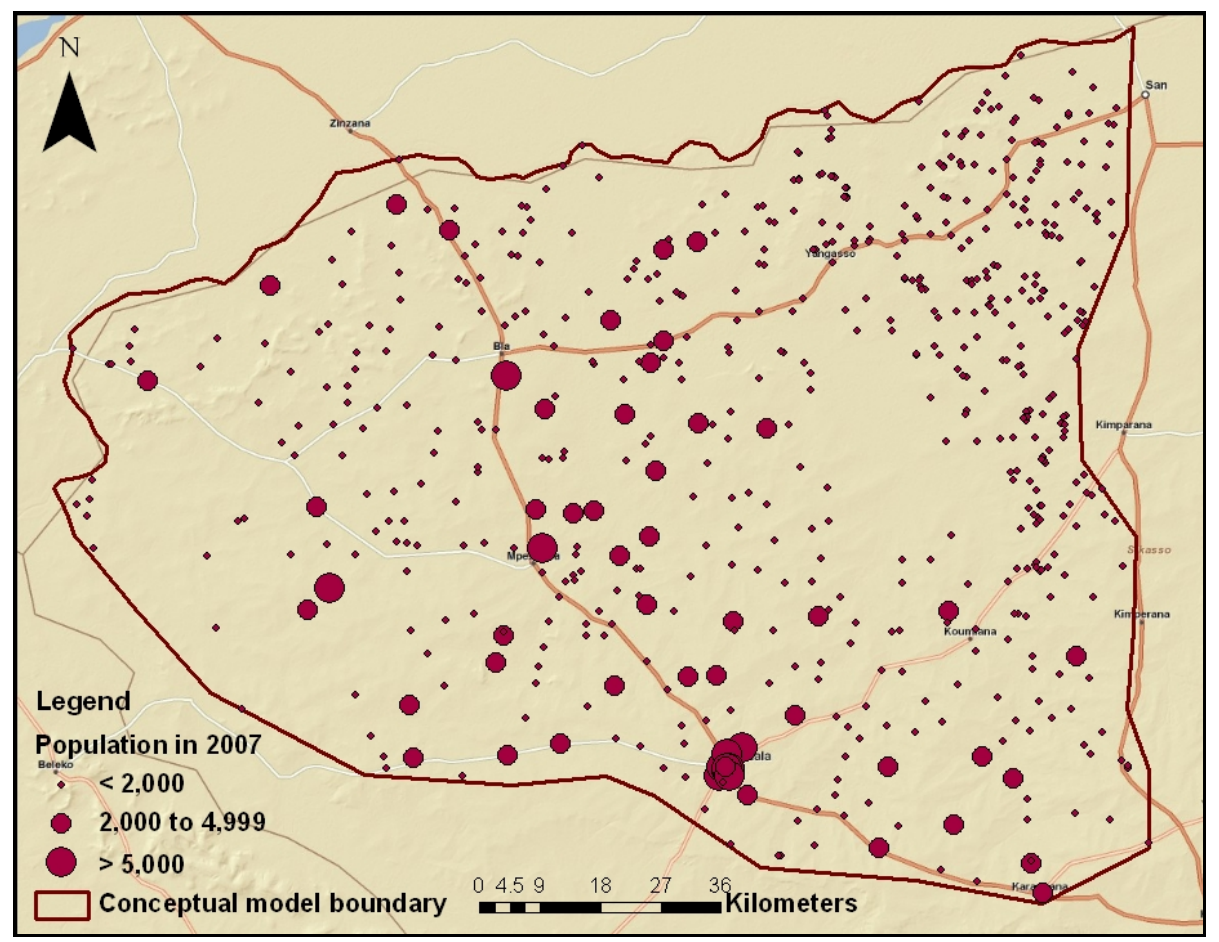


Figure 4. Calculated population in Bani study area during 2040, which is the end of the modeling scenarios.

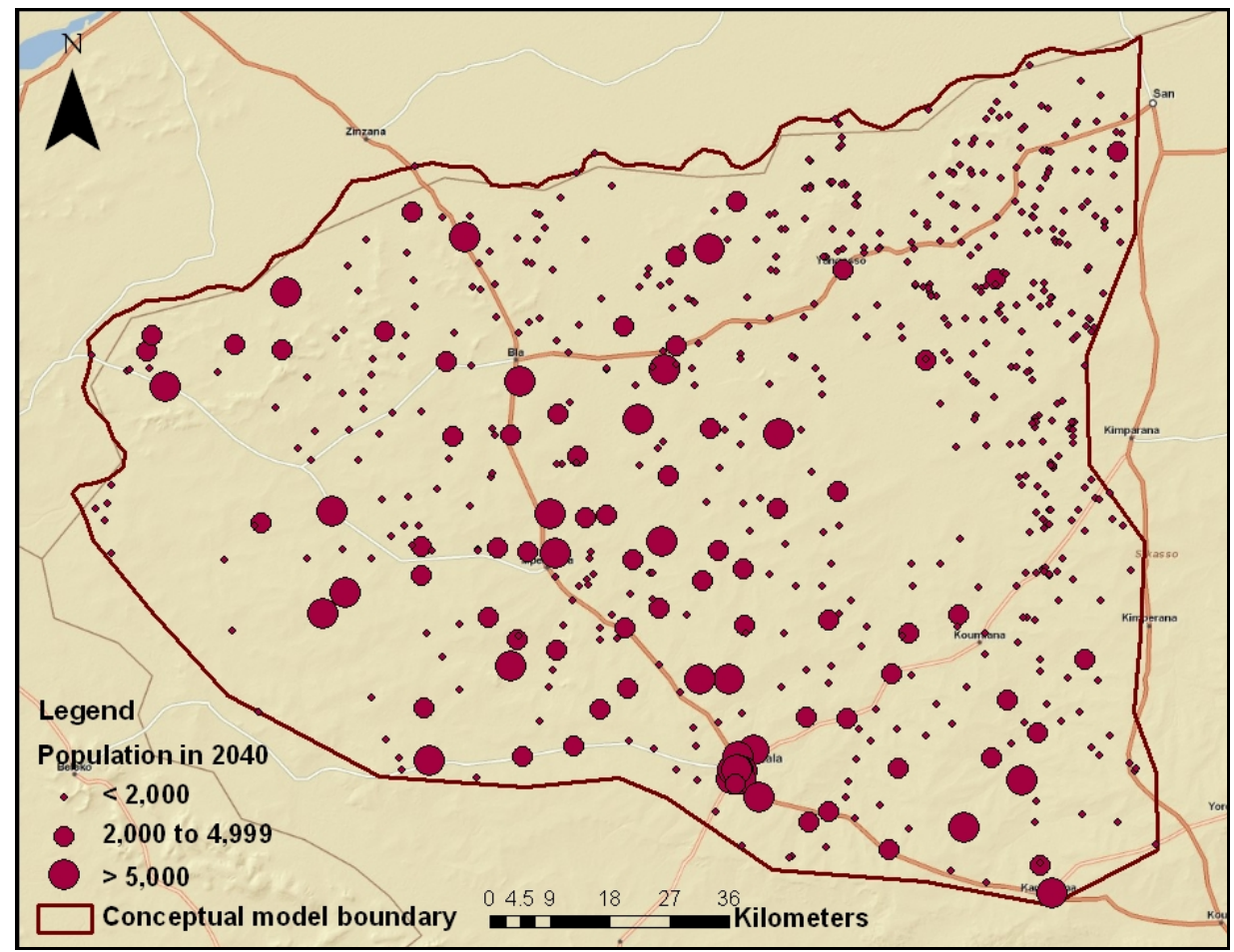

Because sources of groundwater vary, ranging from hand-dug wells and hand-pumps to piped networks supplied by boreholes, extraction rates are based on average liter per capita per day (lpcpd) water use and forward projections of the 1998 census data. General estimates of African reliance on a groundwater source ranges from 50 to $75 \%$ [12]. In 1996, approximately 50\% of the population in the Bani area had access to some type of groundwater source [5] and that percentage has likely increased during the past 15 years. Millenium Development Goal (MDG) 7c included a target to halve the proportion of population without access to safe drinking water by 2015 (UN, 2010). At the current rate of water provision, however, the MDG target will not be reached by 2015 . Numerous governmental and non-governmental Water, Sanitation, and Hygiene (WASH) groups are working in the Bani area and in hopes that additional resources will be put towards provision of water during the next 30 years, it is anticipated that every inhabitant of the Bani study area has access to potable water ("universal access") from a groundwater source by 2040.

Surveys reveal current domestic water use in rural areas of Mali to be $21 \mathrm{lpcpd}$, with seasonal and geographical variations [13,14]. Guidelines for potable water supply in Mali are 50, 41, and 20 lpcpd in urban, semi-urban, and rural areas, respectively [5]. WASH groups working to improve human health do so by instructing with use of potable water for washing, bathing, food preparation, etc., and the minimum amount suggested for improved human health is 50 lpcpd [15]. Water use is not limited to domestic use only. The surveys reveal that domestic use accounts for 55\% of the total volume extracted, while the remainder is for livestock and gardening (Figure 5). The total amount, then, is 90 lpcpd (50 lpcpd domestic and 40 lpcpd livestock and gardening). Each community is assigned an extraction rate based on its projected population and 90 lpcpd consumption. 


\subsection{Development}

As the population of Mali grows, and the economy continues to develop, it is likely that groundwater will be increasingly used for industry and agriculture (manufactured goods and crops for self-sufficiency or export). To have more reliable, and potentially increased, crop yield "efforts should be intensified to support water resource and small-scale irrigation development" [16]. For instance, the yield of cotton, which has potential as a cash crop for export, can be made more reliable and potentially increased by supplementing it with irrigation water in addition to rainfall.

Worldwide, the agricultural sector accounts for $70 \%$ of water extraction, while less than $5 \%$ of African land is currently under irrigation [12]. Mechanized systems, already in place at some boreholes, can be optimized to extract groundwater for agriculture or industry at greater rates than cemented wells or hand-pumps. Under this scenario, domestic use is no longer the majority of water consumed. As development occurs, livestock and gardening formerly associated with rural areas now becomes incorporated into large-scale agriculture. Water use statistics for low-and middle income countries, such as Mali, are: domestic $8 \%$, industrial 10\%, and agricultural 82\%. With 50 lpcpd now representing $8 \%$ of water use, the total volume is $625 \mathrm{lpcpd}$ (Figure 5).

Figure 5. Proportions of water use as percent of total.
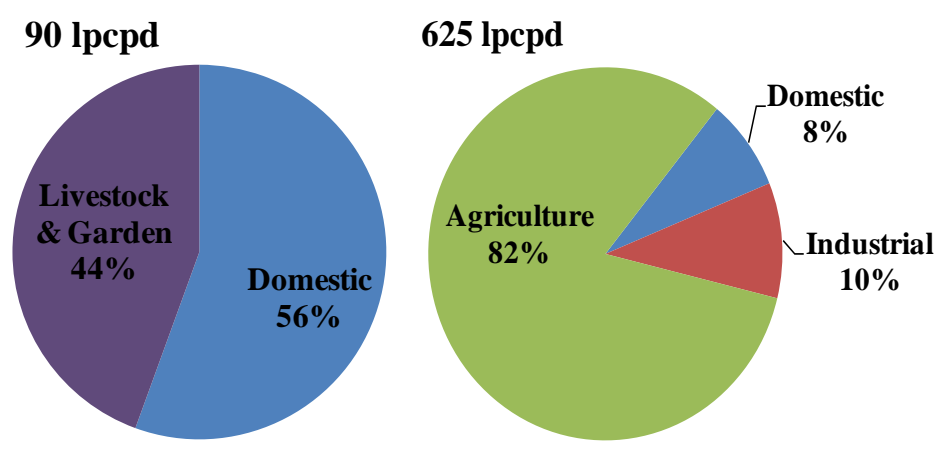

\subsection{Climate Variability}

Climate variability as precipitation fluctuations indicate a tendency toward aridity in Mali beginning in the 1960s. Precipitation and ecological isohyets have shifted south since 1961, with an overall reduction of precipitation of approximately $100 \mathrm{~mm} \mathrm{yr}^{-1}$ [17]. The $400-\mathrm{mm}$ precipitation isohyet has moved south about $50 \mathrm{~km}$, while the $800-\mathrm{mm}$ isohyet has moved south about $100 \mathrm{~km}$, and the 1,200-mm isohyet has disappeared from Mali and Burkina Faso [18].

This reduction of precipitation suggests a decrease of groundwater recharge, ultimately resulting in decrease of groundwater stored and available. Recharge to groundwater most likely takes place via infiltration of precipitation into unconsolidated sediments and through fractures and the rock matrix [19]. In the Bani modeling area, there are no known studies using direct measurements, water-balance methods, tracer techniques, or empirical methods to establish recharge processes or to estimate recharge amounts. Groundwater recharge in this and surrounding areas is reported as 6 to $18 \%$ of mean annual precipitation, though the lower end is recommended for modeling purposes [20,21]. 
Precipitation data, which correlate with groundwater recharge for the area, are for the town of San (Figure 1). Records from San, available from 1979 to 2006 from NCAR, indicate that average annual precipitation for this period is $505 \mathrm{~mm} \mathrm{yr}^{-1}$. Calculating $6 \%$ of $505 \mathrm{~mm} \mathrm{yr}^{-1}$ gives a recharge value of

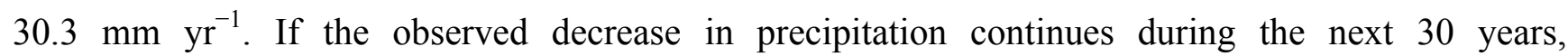
precipitation is gradually reduced by $100 \mathrm{~mm} \mathrm{yr}^{-1}$ to $405 \mathrm{~mm} \mathrm{yr}^{-1}$. Calculating $6 \%$ of $405 \mathrm{~mm} \mathrm{yr}^{-1}$ gives a recharge value of $24.3 \mathrm{~mm} \mathrm{yr}^{-1}$.

It is not entirely clear, however, that the trend of decreasing precipitation is continuing. Nicholson [22] suggests some recovery of precipitation from 1998 to 2003 in comparison with extremely dry conditions experienced from 1968 to 1997, though not a recovery to the extremely wet conditions experienced from 1950 to 1959. Nicholson's study examines mean annual precipitation by $2^{\circ}$ longitudinal zones. The Bani study area is approximately between two of these zones, so the range of precipitation is interpolated to be 540,514 , and $405 \mathrm{~mm} \mathrm{yr}^{-1}$ for wet, recovery, and dry years, respectively. If a recovery is currently occurring, and the trend of recovery continues, then the recovery recharge value is $30.8 \mathrm{~mm} \mathrm{yr}^{-1}\left(6 \%\right.$ of $\left.514 \mathrm{~mm} \mathrm{yr}^{-1}\right)$. Another possibility is that recovery ends in 2011, and is then followed by random variations of precipitation ranging from wet to dry (540 to $405 \mathrm{~mm} \mathrm{yr}^{-1}$ ) until 2040 .

\section{Experimental Section}

\subsection{Model Scenarios}

Input parameters to the model for the four scenarios are described below. Population growth, development as urbanization, and climate variability scenarios (summarized in Table 2) are as follows:

Table 2. Summary of the four model scenarios.

\begin{tabular}{|l|c|c|c|c|c|}
\hline \multicolumn{1}{|c|}{ Scenario } & Population & Consumption & Precipitation & \multicolumn{2}{c|}{ Extraction } \\
\hline & $(\mathrm{M})$ & $(\mathrm{lpcpd})$ & $(\mathrm{mm})$ & $\left(\mathrm{M} \mathrm{m}^{3} \mathrm{yr}^{-1}\right)$ & $(\%$ of precipitation $)$ \\
\hline 1 Population doubles & $0.59 \rightarrow 1.18$ & 90 & 505 & $23.1 \rightarrow 39.7$ & $0.32 \rightarrow 0.55 \%$ \\
\hline 2 Agriculture \& Industry & 1.18 & 695 & 505 & 222 & $3.1 \%$ \\
\hline 3 Drying trend & 1.18 & 695 & 405 & 222 & $3.8 \%$ \\
\hline 4 Variable Precipitation & 1.18 & 695 & $405-540$ & 222 & $3.0-3.8 \%$ \\
\hline
\end{tabular}

Scenario 1 considers population growth, urbanization, and universal access to the minimum requirement of potable water. The population doubles from approximately 0.59 million (M) in 2007 to $1.18 \mathrm{M}$ by 2040. All inhabitants use $90 \mathrm{lpcpd}$, of which the majority is domestic use. The extraction rate increases from $23.1 \mathrm{M} \mathrm{m}^{3} \mathrm{yr}^{-1}$ to $39.7 \mathrm{M} \mathrm{m}^{3} \mathrm{yr}^{-1}$, which is 0.32 and $0.55 \%$, respectively, of mean annual precipitation.

Scenario 2 is an extension of Scenario 1, adding development as industrialization and intensification of agriculture through irrigation of pumped groundwater. The population of $1.18 \mathrm{M}$ uses $625 \mathrm{lpcpd}$, of which the majority is for agriculture. The extraction rate increases to $222 \mathrm{M} \mathrm{m}^{3} \mathrm{yr}^{-1}$, which is $3.1 \%$ of mean annual precipitation.

Scenario 3 is an extension of Scenario 2, adding a drying trend of precipitation. Precipitation decreases from 505 to $405 \mathrm{~mm} \mathrm{yr}^{-1}$ by 2040. Consequently, recharge decreases from 30.3 to $24.3 \mathrm{~mm} \mathrm{yr}^{-1}$. 
The population of $1.18 \mathrm{M}$ uses $625 \mathrm{lpcpd}$, and the extraction rate remains $222 \mathrm{M} \mathrm{m}^{3} \mathrm{yr}^{-1}$. Extraction forms a larger proportion of mean annual precipitation, increasing from 3.1 to $3.8 \%$.

Scenario 4 considers population growth, universal access to the minimum requirement of potable water, irrigation for agriculture, and a recovery of precipitation followed by variation of precipitation. Precipitation is $513 \mathrm{~mm} \mathrm{yr}^{-1}$ from 2007 until 2011 and then varies between 540 to $405 \mathrm{~mm} \mathrm{yr}^{-1}$ until 2040. Under this scenario, extraction ranges from 3.0 to $3.8 \%$ of mean annual precipitation.

\subsection{Discussion of Scenarios}

The scenarios depict increasing consumption of water, though not at a rate that follows population growth. In Scenario 1, population growth, development as urbanization, and universal access to the minimum requirement of potable water nearly double the rate of consumption. Extraction remains less than $1 \%$ of mean annual precipitation, which represents a relatively small percentage of the groundwater system. In general, extraction rates in this scenario are too small to affect the groundwater system.

The addition of agriculture and industry as groundwater consumers in Scenario 2 increases the volume of extraction by an order of magnitude as compared with Scenario 1. The addition of a drying trend in Scenario 3 does not increase the volume of groundwater extraction. Instead, it reduces the amount of groundwater available in the system from precipitation, so extraction increases as proportion of mean annual precipitation from 3.1 to $3.8 \%$. Comparison of Scenarios 1, 2, and 3 indicate that use of groundwater for agriculture and industry increases consumption of water more than either population growth or a drying trend. Concentrated pumping is in local areas results in water level declines.

Figure 6 shows the model depiction of groundwater levels in Scenario 3. In the model, land surface elevation ranges from approximately 290 to 370 masl and groundwater levels are initially approximately $20 \mathrm{~m}$ below land surface. At the end of Scenario 3, lower levels of groundwater (darker blue, approximately $40 \mathrm{~m}$ below land surface) surround communities of 10,000 inhabitants or more. One of these communities is Koutiala, which is shown on the bottom center of Figure 6 (also shown on Figures 1, 2, and 3). It expanded from approximately 94,000 inhabitants to 300,000 by 2040 . Decline of groundwater levels in the model is comparable with drought during in 1982, when groundwater levels in Mali dropped by $10 \mathrm{~m}$ or more [6].

Scenario 4 is an extension of Scenario 3, but considers a recovery of precipitation followed by variation of precipitation. Extraction varies between 3.0 and $3.8 \%$ of mean annual precipitation. At a well-field in the Upper-Northern Region of Ghana, which experiences similar hydrogeologic and climatic conditions, groundwater extraction in excess of 5\% of mean annual precipitation resulted in aquifer dewatering [23]. Though extraction is not greater than $5 \%$ of mean annual precipitation and does not exceed the recharge rate of $6 \%$ of mean annual precipitation, Scenario 3 depicts that concentrated pumping in and surrounding larger communities results in groundwater level declines.

Though the circumstances presented in these four scenarios are based on conservative estimates of hydrogeological parameters presented in the literature, there are several considerations with respect to this study. Two aquifer input parameters - specific yield and specific storage - may alter the water balance for the groundwater system. Conservative estimates for these parameters presented in the 
literature are used in this study, since hydrogeologic parameters are not very well known for the Bani area. Less conservative values of specific yield and specific storage allow for greater groundwater storage in the model of the aquifer. The time-series groundwater level data that are currently being collected in the study area will help develop better estimates for these and other hydrogeologic values.

Figure 6. Groundwater levels in Scenario3 during 2040. Dark blue depressions of very low groundwater levels coincide with larger communities of population greater than 5,000.

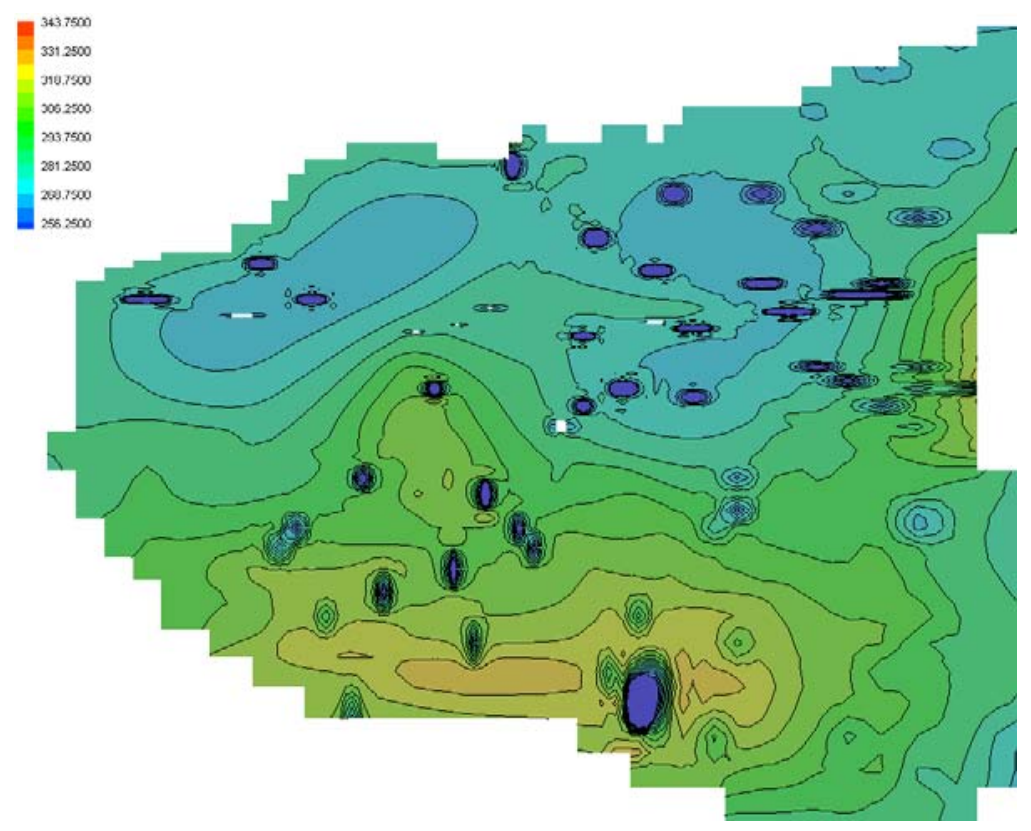

Also, groundwater recharge is calculated as $6 \%$ of mean annual precipitation, but may be up to $18 \%$ of mean annual precipitation in the Sahel region (a larger recharge volume would offset the proportion of extraction rates). The relationship between precipitation and recharge to groundwater is not entirely straightforward and is not well understood in this area. Too little or too much precipitation may either evaporate or form runoff, respectively, and not recharge to groundwater. Recharge to groundwater may occur erratically given the large inter-annual variability of precipitation.

\section{Conclusions}

The Bani model is a case study for evaluating groundwater availability in light of increasing population, development, and climate variability. By 2040, population growth, climate variability, and development as urbanization, agriculture, and industry creates scenarios in which groundwater extraction an increasingly larger percentage of mean annual precipitation and the groundwater system. Comparison of Scenarios 1, 2, 3, and 4 suggest that use of groundwater for agriculture and industry increases consumption of water more than either population growth or a drying trend. Consumption from agriculture and industry increases extraction rates from less than 1 to $3.8 \%$ of mean annual precipitation (approximately 23.1 to $222 \mathrm{M} \mathrm{m}^{3} \mathrm{yr}^{-1}$ ). In Scenario 1, extraction rates are likely too small to affect the regional water balance. However, as extraction rates increase beyond $3 \%$ in Scenarios 2, 3 , and 4 , concentrated pumping in local areas may result in water level declines. 
Increased demand for water due to development itself, as agriculture, industry, and urbanization, is a topic warranting further study. Agricultural projects, already existing in the Bani area, that utilize small dams and diversions of surface water into canals may increase in size and number in the future. While agriculture and industry increase the demand for water, urbanization may increase domestic consumption due to availability of safe water from a growing pipe network. For instance, water use in an urban house (with garden) can be up to 400 lpcpd [14]. In semi-urban areas, or in mid-size communities, mechanized pumps and pipe networks are preferred, despite high maintenance costs. Surveys of community members reveal the preference due to ease of use (less manual effort). availability of sufficient volume of water, and community status [13,24]. Women, who have the responsibility of fetching water, perceive these systems "more efficient in reducing the drudgery of drawing water" [13]. As Mali, and other nations, continue to develop, and the practice of fetching water from a hand-pump or cemented well is replaced by a stand-pipe or piped network, demand for water is likely to increase.

Increasing access to sustainable, safe water improves human health and has socioeconomics benefits. Providing sustainable, safe water sources, while managing water as a resource, is an ongoing challenge to developing nations. As the Bani study continues, more data on hydrogeological parameters will lead to enhanced study scenarios. For example, incorporation of surface water sources, as they evolve for water supply, is anticipated in future Bani study scenarios. Finally, additional surveys of water use in urban and rural areas provide great insight into water resource sustainability studies.

\section{Acknowledgements}

This research was sponsored by a Fulbright Scholarship and the Conrad N. Hilton Foundation. Thanks to World Vision Mali and the Mali Rural Water Project for providing support in Mali. Much appreciation goes to the communities in the study area. Special thanks to Samuel Diarra, Jenny McConville, and Cajetan Kasei for their time and knowledge. Additional assistance is given by DRI. The GRDC data come from the center located at D-56002 Koblenz, Germany. The NCAR data were provided by the Data Support Section of the Computational \& Information Systems Laboratory (formerly SCD) at the National Center for Atmospheric Research. NCAR is supported by grants from the National Science Foundation.

\section{References and Notes}

1. Gleick, P. The changing water paradigm: A look at twenty-first century water resources development. Water Int. 2000, 25, 127-138.

2. United Nations Development Programme. Human Development Report, 2006. Available online: http://hdr.undp.org/en/reports/global/hdr2006/ (accessed on 1 May 2007).

3. United Nations Children's Fund. The State of the World's Children 2006. Available online: http://www.unicef.org/sowc06/fullreport/full_report.php (accessed on 1 May 2007).

4. Younger, P. Groundwater in the Environment: An Introduction; Blackwell: Oxford, UK, 2006. 
5. N'Djim, H.; Doumbia, B. Case study: Mali population and water issues. In Water and Population Dynamics: Case Studies and Policy Implications; De Sherbinin, A., Dompka, V., Eds.; American Association for the Advancement of Science: Washington, DC, USA, 1998; Available online: http://www.aaas.org/international/ehn/waterpop/mali.htm (accessed on 1 March 2010).

6. Bricquet, J.; Bamba, F.; Mahe, G.; Toure, M.; Olivry, J. Évolution Récente des Ressources en Eau de l'Afrique Atlantique. Rev. Sci. de L'Eau 1997, 3, 321-337.

7. Wong, C.; Roy, M.; Duraiappah, K. Connecting Poverty and Ecosystem Services: Focus on Mali-A Series of Seven Country Scoping Studies; International Institute for Sustainable Development and the United Nations Environment Programme: Winnipeg, Canada, 2005; Available online: http://www.iisd.org/pdf/2005/economics_poverty_mali.pdf(accessed on 2 June 2007).

8. Lutz, A.; Thomas, J.; Pohll, G.; Keita, M.; McKay, A. Sustainability of groundwater in Mali, West Africa. Environ. Geol. 2009, 58, 1441-1450.

9. Shahin, M. Hydrology and Water Resources of Africa; Kluwer Academic Publishers: Dordrecht, The Netherlands, 2002; Water Science and Technology Library Series, Volume 41.

10. Lutz, A. User's Manual for MRWP Database; Desert Research Institute: Reno, NV, USA, 2006.

11. Harbaugh, A.; Hill, M.; McDonald, M. MODFLOW-2000, The U.S. geological survey modular ground-water model. In User Guide to Modularization Concepts and the Ground-Water Flow Processes; United States Geological Survey: Reston, VA, USA, 2000.

12. Taylor, R.; Koussis, A.; Tindimugaya, C. Groundwater and climate in Africa-A review. Hydrolog. Sci. J. 2009, 54, 655-664.

13. Gleitsmann, B.; Kroma, M.; Steenhuis, T. Analysis of a rural water supply project in three communities in Mali: Participation and sustainability. Nat. Resour. Forum 2007, 31, 147-150.

14. McConville, J. Peace Corps Volunteer, Zambougou, Mali. Personal communication, 2006 and 2007.

15. Gleick, P. Basic water requirements for human activities: Meeting basic needs. Water Int. 1996, 21, 83-92.

16. Perret, S. Climate Change and African Agriculture; Centre for Environmental Economics and Policy in Africa: Pretoria, South Africa, 2006; Available online: http:/www.ceepa.co.za/docs/ POLICY\%20NOTE\%2024.pdf (accessed on 5 June 2007).

17. Kasei, K. Savannah Agricultural Research Institute, Nyankpala, Ghana. Personal communication, 2005.

18. Paturel, J.; Ouedraogo, M.; Servat, E.; Mahe, G.; Dezetter, A.; Boyer, J. The concept of rainfall and streamflow normals in West and Central Africa in a context of climatic variability. Hydrolog. Sci. J. 2003, 481, 125-137.

19. Gyau-Boakye, P. Sources of rural water supply in Ghana. Water Int. 2001, 261, 96-104.

20. Leduc, C.; Bromley, J.; Schroeter, P. Water table fluctuation and recharge in semi-arid climate: Some results of the HAPEX-Sahel hydrodynamic survey (Niger). J. Hydrol. 1997, 188-189, 123-138.

21. Diluca, C.; Muller, W. Evaluation Hydrogeologique des Projets d'Hyraulique en Terrains Cristallins du Bouclier Ouest Africain; Bundesanstalt fur Geowissenschaft und Rohstoffe: Hanover, Germany, 1985; Cooperation Technique Projet No. 82.2060.0. 
22. Nicholson, S. On the question of the "recovery" of the rains in the West African Sahel. J. Arid Environ. 2005, 63, 615-641.

23. Bannerman, R.; Ayibotele, N. Some critical issues with monitoring crystalline rock aquifers for groundwater management in rural areas. In Challenges in African Hydrology and Water Resources, Proceedings of the Harare Symposium, Harare, Zimbabwe, July 1984; Walling, D., Foster, S., Wurzel, P., Eds.; International Association of Hydrological Sciences: Wallingford, UK, 1984; Volume 144, pp. 47-56.

24. Fomba, M.; Sanogo, O.; Diabete, B.; Coulibaly, H.; Traore, K. Etude sue L'Etat d'Eau d'Assasinissement à Bla; Rendus provisoires du maire: Bla, Mali, 2005.

(C) 2010 by the authors; licensee MDPI, Basel, Switzerland. This article is an open access article distributed under the terms and conditions of the Creative Commons Attribution license (http://creativecommons.org/licenses/by/3.0/). 